\title{
Reinstatement of short-latency responses after asymptotic Pavlovian conditioning training by the presentation of an extraneous stimulus
}

\author{
Edgar H. Vogel \\ Universidad de Talca, Talca, Chile and Yale University, New Haven, CT, USA.
}

\begin{abstract}
The purpose of this study was to examine whether the progressive disappearance of short-latency conditioned responses, or inhibition of delay, observed in Pavlovian conditioning with long inter-stimulus intervals, could be reverted by the presentation of a novel stimulus. In one experiment, two groups of rabbits received extensive training with a short ( $250 \mathrm{~ms})$ or a long (1500 ms) tone that overlapped and terminated with a periorbital shock unconditioned stimulus. After training, the presentation of an extraneous stimulus prior to tone onset produced a reinstatement of short latency CRs in the group trained with the long CS, but did not affect CR latency in the group trained with the short CS.

This finding is consistent with Pavlov's (1927) view that conditioning with long conditioned stimuli involves the acquisition of response tendencies in the early portion of the stimulus that are subsequently suppressed by the development of an inhibitory process.
\end{abstract}

Key words: Inhibition of delay, conditioning, temporal discrimination, eyeblink conditioning, timing

\section{INTRODUCTION}

Inhibition of delay is an empirical fact of Pavlovian conditioning that consists of an increase in the latency of the conditioned response $(\mathrm{CR})$ over training. The first systematic observations of this phenomenon date back to 1927 in Pavlov's studies of salivary conditioning in dogs. He noticed that over the course of training with a long conditioned stimulus (CS) that precedes the unconditioned stimulus (US, typically food) there was a gradual reduction in the amount of saliva elicited during the early portion of the CS, and an increase in the amount of saliva elicited during the latter portion of the CS. Since the responses that originally occurred in the early portion of the CS seemed to be "inhibited" as training progressed, he proposed the term "inhibition of delay" (Pavlov, 1927).

During the 1960s, there was marked interest among theorists in the nature of the inhibition of delay reported by Pavlov. Consequently, Pavlov's findings were frequently analyzed and scattered evidence was reported in several theoretical papers (e.g., Kimmel, 1965; Prokasy, 1965; Sheffield, 1965). For instance, Sheffield (1965) reported the lengthening of the latency of conditioned salivation in a dog trained with a 4-sec CS and Kimmel (1965) observed a virtually linear increase in the latency of human Galvanic Skin Response with a light CS followed by a fi nger shock US.

For early theoreticians, inhibition of delay is closely related to other temporal phenomena of Pavlovian conditioning, such as the fact that the latency of onset and peak of the CR increases with the CS-US interval, and that the prominent time of occurrence of the CR is at the US locus (Bitterman, 1964; Davis et al., 1989; Gallistel and Gibbon, 2000; Mauk and Ruiz, 1992). Nevertheless, although these observations are not incompatible with the notion of inhibition of delay, and probably are regulated by partially common mechanisms of temporal discrimination, they should not be taken as indicative that an excitatory tendency has been inhibited during the early portion of the CS. Vogel et al. (2003) pointed out that a genuine demonstration of inhibition of delay should include both, evidence of conditioned responses in the early portion of the CS at initial stages of training, presumably due to the development of the so-called "excitatory CS-US associations", and a subsequent suppression of these responses at the end of conditioning, presumably due to the progressive development of the so- called "inhibitory CS-US associations" in the early portion of the CS.

As a theoretical interpretation of inhibition of delay, Pavlov (1927) proposed that training with a single CS can be seen as a situation where animals learn to discriminate among a complex combination of hypothetical elements present over the duration of the CS. This implies that the CS is made up of a number of components that establish separable associations with the US. A critical aspect of this CS representation is the assumption that the pattern of activity of each element varies in time following CS initiation, such that they are differentially eligible for reinforcement and non-reinforcement depending on their temporal location with respect to the US.

Figure 1 presents an example of how the temporal discrimination hypothesis can be implemented in modern theories of Pavlovian conditioning (e.g., Vogel et al., 2003). It is assumed that some CS-elements have a more positive correlation with reinforcement across trials than other elements do, in such a way that they may develop comparatively more associative strength. In Figure 1, processing of the CS is represented by a set of binary elements, which can be in an "on" state of activity (represented as a black circle) or in an "off" state of activity (represented as a white circle), at any time during the CS. The figure depicts the pattern of activity of six elements in a training situation in which the US is presented in the last temporal segment of the CS. Although the elements differ in their loci of activity, they can be classified roughly into three categories. The "A-elements" that are solely activated at the US locus, the "X-elements" that are 
activated in both the US locus and at some other moments, and the "B-elements" that are activated only when the US is not present. Thus, temporal discrimination would be an instance of an $\mathrm{AX}+\mathrm{BX}$ discrimination in which the elements $\mathrm{A}, \mathrm{B}$ and $X$ develop differential associations with the US, according to their differential temporal contiguity with the US.

Activity of binary elements

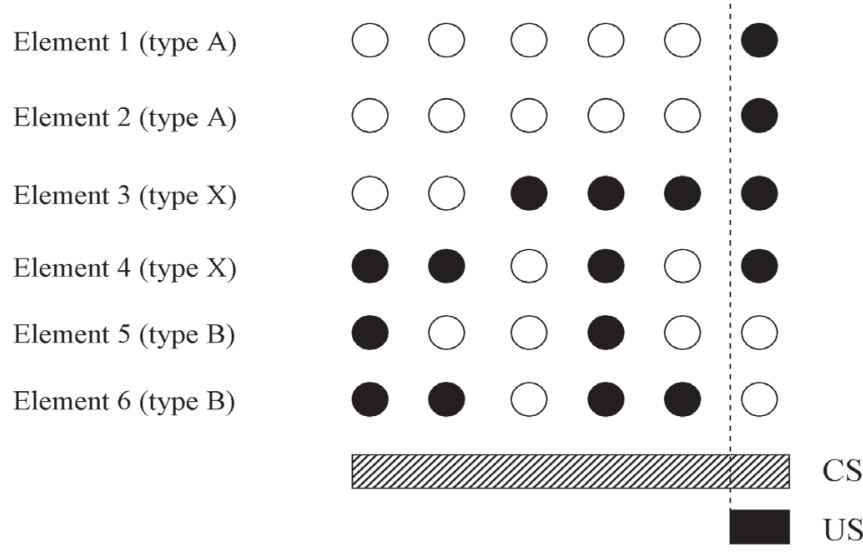

Figure 1. Schematic representation of the temporal discrimination hypothesis of inhibition of delay: It is assumed that the CS activates a sequence of binary elements whose state of activity varies between off (white circles) and on (black circles) states over the duration of the CS. The black rectangles at the bottom represent the duration of the CS and the US.

According to the theoretical analysis presented above, inhibition of delay is the result of conditioned inhibition to these CS elements that are consistently activated in absence of the US (the "B" elements) in position of overlap with those elements that are partially associated with the US (the " $X$ " elements). This notion implies that excitatory and inhibitory CS-US associations coexist in the early part of the CS. Very few studies, however, have evaluated the nature of the association existing in the early portion of the CS.

Evidence of inhibition in the early portion of the CS has been provided by means of a summation test by Rodnick (1937). He demonstrated that the human eyelid conditioned response to a brief vibratory CS was significantly diminished in amplitude when presented 5-sec after the onset of a 21-sec light that had been paired with a wrist shock US, as compared to trials without the light CS. Although the light CS produced some decrement in the conditioned eyelid response before it was paired with the US, this decrement was reliably greater after it had been paired with the US.

Pavlov (1927) suggested another method to detect excitatory and inhibitory tendencies in the early portion of the CS. He reported that animals that had developed inhibition of delay would show a reappearance of short latency CRs in the presence of an extraneous, "disinhibiting" stimulus. The disinhibition procedure was further explored by Rescorla (1967, Experiment 2) in dogs trained to avoid a CS paired with footshock. Inhibition of delay was demonstrated by a progressive reduction in the rate of avoidance responses to the early portion of the CS. In the last session of training, a novel stimulus presented during the early portion of the CS produced a uniform increase in the response rate, whereas it did no affect responding when it was presented in the later portion of the CS.

Apart from the early reports described above, the evidence on the existence of inhibition of delay in other preparations is controversial. That is, although a progressive increase in the latency of CR has been demonstrated in the conditioned suppression of instrumental behavior in rats (Hammond and Maser, 1970; Hendry and Van Toller, 1965; Millenson and Hendry, 1967; Smith et al., 1969; Zielinsky, 1966) and fear conditioning in dogs (Rescorla, 1967), in human and rabbit eyelid conditioning, the literature is ambiguous. For instance, while some studies of human eyelid conditioning reported increases in the latency of CR (Runquist and Muir, 1965) others showed decreases (Ebel and Prokasy, 1963; Hilgard and Campbell, 1936; Subosky, 1967). Likewise, most research conducted with rabbit eyelid conditioning reports that the $\mathrm{CR}$ latency decreases with training towards an asymptote at about half of the CS duration (e.g., Coleman and Gormezano, 1971; Gormezano, 1972; Salafia et al., 1974; Salafia et al., 1975; Schneiderman, 1966; Schneiderman and Gormezano, 1964; Smith et al., 1969), which is the opposite of an inhibition of delay effect.

On the face of these controversial results, Vogel et al. (2003) suggested that the predominant absence of inhibition of delay seen in rabbit eyeblink conditioning could be due primarily to the fact that the reported data were based on moderate amounts of training, typically between eight and ten sessions, and with relatively short CSs, which might not be sufficient to observe the development of inhibition of delay. In agreement with this reasoning, Vogel et al. reported two experiments that demonstrated inhibition of delay when rabbits were trained with relatively long but not with short CSs. Specifically, in Experiment 2, two groups of rabbits received 20 daily sessions of eyelid conditioning training, in which a tone CS overlapped and terminated with a shock US. Each session consisted of 56 reinforced trials and 6 nonreinforced trials. For the animals in the group designated as "short CS group" $(n=8)$, the CS was $250 \mathrm{~ms}$ duration, while in the group designated as "long CS group" ( $\mathrm{n}=7)$, the CS was $1500 \mathrm{~ms}$ duration. Inhibition of delay was apparent in animals trained with the long $1500 \mathrm{~ms}$ CS but not in animals trained with the shorter- $250 \mathrm{~ms} C S$, whose CR latency decrease, rather than increased over training.

The present experiment was designed to extend the findings of Vogel et al. (2003) by investigating a disinhibition procedure in the same 15 animals that were trained with short and long intervals. The rationale of the experiment is that if the animals of the two groups of Vogel et al. (Experiment 2) had developed differential inhibition of delay, and the difference was due to differential conditioned inhibition, then the presentation of an extraneous stimulus prior to the initiation of the CS (the disinhibition procedure) may have a differential effect on the two groups. Specifically, it was expected that there would be a reinstatement of short latency CRs in the 1500 ms animals, which had presumably developed inhibition of delay, but there would be no effect on the animals trained with the $250 \mathrm{~ms}$ CS, which did not develop inhibition of delay.

\section{METHOD}

Animals

Male New Zealand white rabbits (Oryctolagus cuniculus; $\mathrm{n}=16$ ) weighing between 2 and $3 \mathrm{~kg}$, were individually housed and 
maintained with ad libitum food and water, except during experimental sessions

\section{Apparatus}

The experiment was conducted in $66 \mathrm{~cm} \times 48 \mathrm{~cm} \times 48 \mathrm{~cm}$ isolation chambers. Each chamber was completely lined with aluminium foil to provide a homogeneous visual surrounding and illuminated by a $1 \mathrm{~W}$ neon bulb. Ventilation fans provided a constant background masking noise that raised the ambient sound pressure level to approximately $70 \mathrm{~dB}$ (re $20 \mathrm{uN} / \mathrm{m} 2$ ) in each chamber. During the experimental sessions, the rabbit was loosely restrained within a $51 \mathrm{~cm} \times 18 \mathrm{~cm} \times 14 \mathrm{~cm}$ Plexiglas box, from which its head protruded. The conditioned stimulus was a $3000-\mathrm{Hz} 90-\mathrm{dB}$ tone that coterminated with a $50-\mathrm{ms}$ 3-mA shock US delivered to the right paraorbital region. The "extraneous stimulus," (see procedure below) was a $1000 \mathrm{~ms}$ sequence of alternating presentations of a $250 \mathrm{~ms}$ light and a $250 \mathrm{~ms}$ vibrotactile stimulus applied to the animal's chest. The light stimulus was a 12 /sec flashing light generated by a strobe lamp located behind the animal so as to reflect diffusely from the walls of the chamber. The vibrotactile stimulus was a 30$\mathrm{Hz}$ oscillation provided by a hand massager mounted on the floor of the restraining box so as to maintain firm contact with the animal's chest. For half of the animals in each group, the extraneous stimulus began with the light and for the other half it began with the vibrotactile stimulus.

Closure of the rabbit's eye was monitored by an adaptation of the photoresistive transducer described by Gormezano and Gibbs (1988). The resulting signal was displayed on a polygraph, adjusted so that a $1 \mathrm{~mm}$ eyelid closure produced a 1 mm deflection of a recording pen.

\section{Procedure}

The experiment is a continuation of the study reported by Vogel et al (2003, Experiment 2). In this previous study, two groups of rabbits received 20 daily sessions of eyelid conditioning training, in which a tone CS overlapped and terminated with a shock US. Each session consisted of 56 reinforced trials and 6 nonreinforced trials. For the animals in the group designated as "short CS group" $(n=8)$, the CS was $250 \mathrm{~ms}$ duration, while in the group designated as "long CS group" (n=8), the CS was 1500 ms duration.

The experiment reported here began the day following the last session of this training. Here a "disinhibition test" was conducted in two successive sessions. Each test session consisted of 56 regular training trials and 7 test trials in which the extraneous stimulus preceded the CS. This stimulus was delivered $1000 \mathrm{~ms}$ prior to the onset of the CS on designated test trials. The test trials were distributed such that one test trial occurred after approximately each 6 training trials.

\section{Scoring}

Movements of the rabbit's eyelid were recorded automatically by a computer program with a frequency of one sample every $10 \mathrm{~ms}$. An eyelid CR was scored when the record indicted an eyelid closure of $0.5 \mathrm{~mm}$ or more, relative to the pre-stimulus baseline, occurring from $50 \mathrm{~ms}$ after the CS onset to $30 \mathrm{~ms}$ after the US onset. The variable of interest was the latency of the $\mathrm{CR}$, computed as the delay between the onset of the CS and the onset of the CR. To avoid distortions due to the different durations of the CS, the latency was expressed as "relative latency" by dividing the latency by the duration of the CS in each group.

\section{RESULTS AND DISCUSSION}

Figure 2 depicts the mean relative latency of the $C R$ for the trials that immediately preceded each test trial with the extraneous stimulus, for the trials that contained the extraneous stimulus, and for the trials that immediately followed the test trials with the extraneous stimulus. Although both groups showed shorter latency of CRs in those trials in which the novel stimulus was presented as compared to the immediately preceding and subsequent trials, the decrease of the Short CS group was negligible, within the range of within session variability, whereas the decrease in the Long CS group was very striking and substantial.

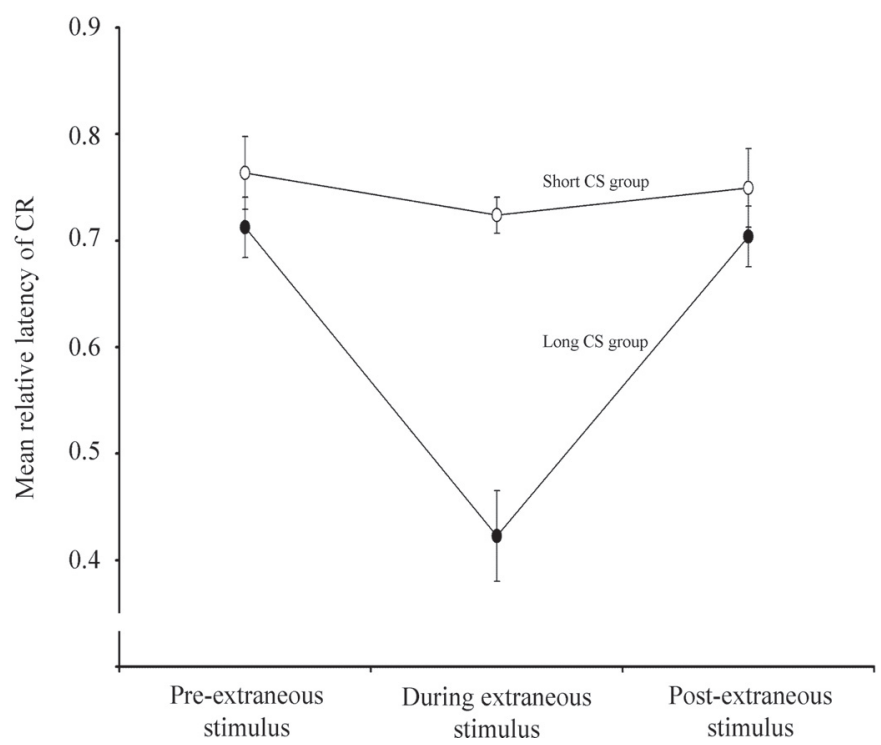

Figure 2. Mean relative latency of $C R$ for the trials that immediately preceded each test trial with the extraneous stimulus, for the trials that contained the extraneous stimulus and for the trials that immediately followed the trials with the extraneous stimulus. The error bars represent the standard error of the means.

Statistical analyses confirmed the reliability of these observations. A 2 (group: $250 \mathrm{~ms}, 1500 \mathrm{~ms}$ ) x 3 (trial type: Pre-extraneous stimulus, during extraneous stimulus, Postextraneous stimulus) ANOVA revealed reliable main effects of group $\left(\mathrm{F}_{11}=9.003, \mathrm{p}=0.009\right)$ and trial type $(\mathrm{F},=33.271, \mathrm{p}$ $<0.001)$ and reliable group $x$ trial type interaction ${ }^{2}\left(\mathrm{~F}_{2,22}=20.93\right.$; $\mathrm{p}<0.001)$.

The main effect of the trial type was due to shorter relative latency of the CR during the extraneous stimulus trials than in the pre-extraneous stimulus and post-extraneous stimulus trials in both groups. Likewise, the main effect of group was due to shorter relative latency of the CR in the long-CS group than in the short-CS one.

The most interesting effect is the trial type $x$ group interaction, which was examined by LSD pairwise comparisons 
of the three trial types in each group. This analysis indicated a reliable decrement in relative latency of CR from the pre and post-extraneous stimulus trials to the extraneous stimulus trials (ps <0.01) in the 1500 ms group, but no reliable effects in the $250 \mathrm{~ms}$ group (ps $>0.239$ ).

Note that the two groups were responding with similar relative latency in regular trials (see the pre-extraneous and post-extraneous stimulus trials in Figure 2). However, just as the groups approached these similar relative latencies from different directions (i.e. one group increased and the other decreased its latency, as reported by Vogel et al., 2003), they also exhibited differential effects of the extraneous stimulus. This is consistent with the notion that an inhibitory process may underlie inhibition of delay and that excitatory and inhibitory associations coexist in the early portion of the CS in those cases in which inhibition of delay occurred.

There are some alternative explanations for the differential effect of the extraneous stimulus in the two groups that should be noted. For example, it can be hypothesized that the decrease in the latency of CR during test trials was due to a CR "potentiation" or "sensitization" caused by the introduction of the extraneous stimulus. According to this interpretation, the reinstatements of short latency responses would not be the result of disinhibition caused by the extraneous stimulus, but rather of the manifestation of an unconditioned response controlled by the latter stimulus. That this effect was evident in the long but not in the short CS group might be attributed to a delay in the potentiation effect, so that it would be more evident when the CR was delayed (in the $1500 \mathrm{~ms}$ group) than when the CR was more immediate (in the 250 ms group). The possibility of CR potentiation could be investigated by replicating the basic design of this experiment and including test trials with several different extraneous stimulus-CS intervals. The hypothetical potentiation effect might be more likely to be seen in the short CS if the extraneous stimulus were lengthened. Likewise, if the extraneous stimulus is a source of response potentiation, it would be expected that a similar increase in responding in the early portion of the CS (or decrease in latency of CR) would be observed in the early stages of training as well as at asymptote. Conversely, if the effect of the extraneous stimulus is to remove inhibition, no effect of the extraneous stimulus should be expected in early stages of training, when inhibition of delay has presumably no yet developed.

It should be pointed out that even if the decrease in the latency of CRs in the $1500 \mathrm{~ms}$ group were due to a removal of inhibition by the extraneous stimulus, this experiment does not comment on why the "disinhibition" effect is obtained. One interpretation is that a novel stimulus specially disrupts inhibition, leaving the excitatory tendency relatively intact, by virtue of inhibition being more labile than excitation, as has been suggested by Pavlov (1927). One could equally argue, however, that the CS elements that developed excitation might be more context-independent than those CS elements that developed inhibition, such that the latter elements would be more readily changed in its perceptual properties by the extraneous stimulus. This view has the advantage that it does no appeal to differential properties of inhibition and excitation, but nevertheless it clearly requires further theoretical and empirical examinations in order to specify the conditions under which these differential effects may occur (see Wagner, 2003; Wagner and Vogel, 2008).

\section{ACKNOWLEDGEMENTS}

Parts of this research were submitted by Edgar H. Vogel to the Graduate School of Yale University in partial fulfi lment of the requirements for the degree of Ph.D. This research was supported in part by National Science Foundation Grant IBN9728896 to Allan R. Wagner, to whom the author is indebted for guidance and help.

\section{REFERENCES}

BITTERMAN ME (1964) Classical conditioning of the goldfish as a function of the CS-US interval. J. Comp Physiol Psychol 58: 359-366.

BONEAU CA (1958) The interstimulus interval and the latency of the conditioned eyelid response. J Exp Psychol 56: 464-471.

COLEMAN SR, GORMEZANO I (1971) Classical conditioning of the rabbit's Oryctolagus cuniculus nictitating membrane response under symmetrical CS-US interval shifts. J Comp Physiol Psychol 77, 447-455.

DAVIS M, SCHLESINGER LS, SORENSON CA (1989) Temporal specificity of fear conditioning: effects of different conditioned stimulusunconditioned stimulus interval on the fear-potentiated startle effect. J Exp Psychol Anim Behav Process 15: 295-310.

EBEL HC, PROKASY WF (1963) Classical eyelid conditioning as a function of sustained and shifted interstimulus interval. J Exp Psychol 65, 52-58.

GALLISTEL R, GIBBON J, (2000) Time, rate and conditioning. Psychol Rev 107: $289-344$.

GORMEZANO I (1972) Investigations of defense and reward conditioning in the rabbit In: BLACK AH, PROKASY WF (Eds) Classical conditioning II. New York: Appleton-Century-Crofts. pp: 151-181.

GORMEZANO I, GIBBS CM (1988) Transduction of the rabbit's nictitating membrane response. Behav Res Methods Instrum Comput 20: 18-22.

HAMMOND LJ, MASER J (1970) Forgetting and conditioned suppression: role of a temporal discrimination. J Exp Anal Behav 13: 333-338.

HENDRY DP, VAN TOLLER C (1965) Alleviation of conditioned suppression. J Comp Physiol Psychol 49: 458-460.

HILGARD ER, CAMPBELL AA (1936) The course of acquisition and retention of conditioned eyelid response in man. J Exp Psychol 19: 227-247.

KIMMEL HD (1965) Instrumental inhibitory factors in classical conditioning In: PROKASY WF (Ed) Classical Conditioning: A symposium. New York: Appleton-Century-Crofts. pp: 148-171.

MAUK MD, RUIZ BP (1992) Learning-dependent timing of Pavlovian eyelid responses: differential conditioned using multiple interstimulus. Behav Neurosci 106: 666-681.

MILLENSON JR, HENDRY DP (1967) Quantification of response suppression in conditioned anxiety training. Can J Psychol 21: 242-252.

PAVLOV IP (1927) Conditioned Reflexes. London: Oxford University Press.

PROKASY WF (1965) Classical eyelid conditioning: experimenter operations, task demands, and response shaping In: PROJASY WF (Ed) Classical conditioning: A symposium. New York: Appleton-Century-Crofts. pp: 208-225.

RESCORLA RA (1967) Inhibition of delay in Pavlovian fear conditioning. J Comp Physiol Psychol 64: 114-120.

RODNICK EH (1937) Does de interval of delay of conditioned responses possess inhibitory properties? J Exp Psychol 20: 507-527.

RUNQUIST WN, MUIR WR (1965) Intrasession decrements in the performance of the classically conditioned eyelid reflex. J Exp Psychol 70: 520-525

SALAFIA WR, DATSON AP, BARTOSIAK RS, HURLEY J, MARTINO LJ (1974) Classical nictitating membrane conditioning in the rabbit Oryctolagus cuniculus as a function of unconditioned stimulus locus. J Comp Physiol Psychol 86: 608-636.

SALAFIA WR, TERRY SW, DATSON AP (1975) Conditioning of the rabbit Oryctolagus cuniculus nictitating membrane response as a function of trials per session, ISI, and ITI. Psychon Soc 6: 505-508.

SCHNEIDERMAN N (1966) Interstimulus interval function in the nictitating membrane response under delay versus trace conditioning. J Comp Physiol Psychol 62: 397-402.

SCHNEIDERMAN N, GROMEZANO I (1964) Conditioning of the nictitating membrane of the rabbit as a function of CS-US interval. J Comp Physiol Psychol 57: 188-195.

SHEFFIELD FD (1965) Relation between classical conditioning and instrumental learning, In: PROKASY WF (Ed) Classical conditioning: A symposium. New York: Appleton-Century-Crofts. pp: 302-322. 
SMITH MC, COLEMAN SR, GORMEZANO I (1969) Classical conditioning of the rabbit's nictitating membrane response at backward, simultaneous, and forward CS-US intervals. J Comp Physiol Psychol 69: 226-231.

SUBOSKY MD (1967) UCS intensity and the latency of the classically conditioned eyelid response. J Exp Psychol 74: 31-35.

VOGEL EH, BRANDON SE, WAGNER AR (2003) Stimulus representation in SOP: II An application to inhibition of delay. Behav Processes 62: 27-48.
WAGNER AR (2003) Context-sensitive elemental theory Q J Exp Psychol, 56B, 7-29

WAGNER AR, VOGEL EH (2008). Configural and elemental processing in associative learning: Commentary on Melchers, Schanks and Lachnit. Behav Processes 77: 446-450.

ZIELINSKY K (1966) Inhibition of "delay" as a mechanism of the gradual weakning of the conditioned emotional response. Acta Neurobiol Exp 37: 299-309. 
